\title{
A NOTE ON SOFT IDEALS AND SOFT FILTERS IN TERNARY SEMIGROUPS WITH INVOLUTION
}

\author{
Mohammad Yahya AbBasi \\ Sabahat Ali Khan \\ AND \\ AkBar Ali \\ Department of Mathematics \\ Jamia Millia Islamia \\ New Delhi-110025, India \\ e-mail: mabbasi@jmi.ac.in \\ khansabahat361@gmail.com \\ akbarali.math@gmail.com
}

\begin{abstract}
The main purpose of this paper is to provide an effective content of theory of ternary semigroups with involution by applying soft set theory concepts. In this paper, we introduce some basic terms and definitions of different ideals in ternary semigroups with involution. Further, we define soft ideals and soft filters in ternary semigroups with involution, and show how a soft set effects on a ternary semigroup with involution with the help of intersection and insertion of sets. We explore some properties using involution theoretic concepts in ternary semigroups for soft ideals and soft filters.
\end{abstract}

Keywords: ternary semigroups with involution, soft ideals, soft filters.

2010 Mathematics Subject Classification: 20N99, 20M12, 03E75.

\section{REFERENCES}

[1] H. Aktas, and N. Cagman, Soft sets and soft groups, Inform. Sci. 177 (200) 27262735 .

doi:10.1016/j.ins.2006.12.008

[2] N. Cagman and S. Enginoglu, Soft set theory and uni-int decision making, Eur. J. Op. Res. 207 (2010) 848-855. doi:10.1016/j.ejor.2010.05.004 
[3] N. Cagman, F. Citak and H. Aktas, Soft int-group and its applications to group theory, Neural Comput. Appl. 21 (2012) 151-158.

doi:10.1007/s00521-011-0752-x

[4] V.N. Dixit and S. Diwan, A note on quasi and bi-ideals in ternary semigroups, Int. J. Math. Sci. 18 (1995) 501-508.

doi:10.1155/S0161171295000640

[5] X. Feng, J. Tang, B Davvaz and Y. Luo, A novel study on fuzzy ideals and fuzzy filters of ordered $\star$-semigroups, J. Intelligent and Fuzzy Systems 33 (2017) 423-431. doi:10.3233/JIFS-161740

[6] J.J. Graham and G.I. Lehrer, Cellular algebras, Invent. Math. 123 (1996) 1-34. doi:10.1007/BF01232365

[7] S. Kar and I. Dutta, Globally determined ternary semigroups, Asian-European J. Math. 10 (2017) 1750038. 13 pages doi:10.1142/S1793557117500383

[8] G.J. Lalitha, Y. Sarala, B.S. Kumar and P. Bindu, Filters in Ternary Semigroups, Int. J. Chem. Sci. 14 (2016) 3190-3194.

[9] D.H. Lehmer, A ternary analogue of abelian groups, Ams. J. Math. 59 (1932) 329-338. doi: $10.2307 / 2370997$

[10] J. Los, On the extending of models I, Fund. Math. 42 (1955) 38-54.

[11] P.K. Maji, R. Biswas and A.R. Roy, Soft set theory, Comput. Math. Appl. 45 (2003) $555-562$. doi:10.1016/S0898-1221(03)00016-6

[12] D. Molodtsov, Soft set theory-first results, Comput. Math. Appl. 37 (1999) 19-31. doi:10.1016/S0898-1221(99)00056-5

[13] T.E. Nordahl and H.E. Scheiblich, Regular $\star$-semigroups, Semigroup Forum 16 (1978) 369-377. doi:10.1007/BF02194636

[14] M. Petrich, The introduction to semigroups (Merrill Publishing Company, Columbus, Ohio, 1973).

[15] A. Sezgin and A.O. Atagun, On operations of soft sets, Comput. Math. Appl. 61 (2011) $1457-1467$. doi:10.1016/j.camwa.2011.01.018

[16] M. Shabir and A. Khan, Fuzzy filters in ordered semigroups, Lobachevskii J. Math. 29(2) (2008) 82-89. doi:10.1134/S1995080208020066

[17] F.M. Sioson, Ideal theory in ternary semigroups, Math. Japan. 10 (1965) 63-84. 
[18] N.E. Wegge-Olsen, K-theory and $\mathrm{C}^{*}$-algebras, Oxford Science Publications (The Clarendon Press, Oxford University Press, New York, A friendly approach, 1993).

Received 16 April 2019

First Revised 23 February 2020

Second Revised 19 April 2020

Accepted 26 April 2020 